
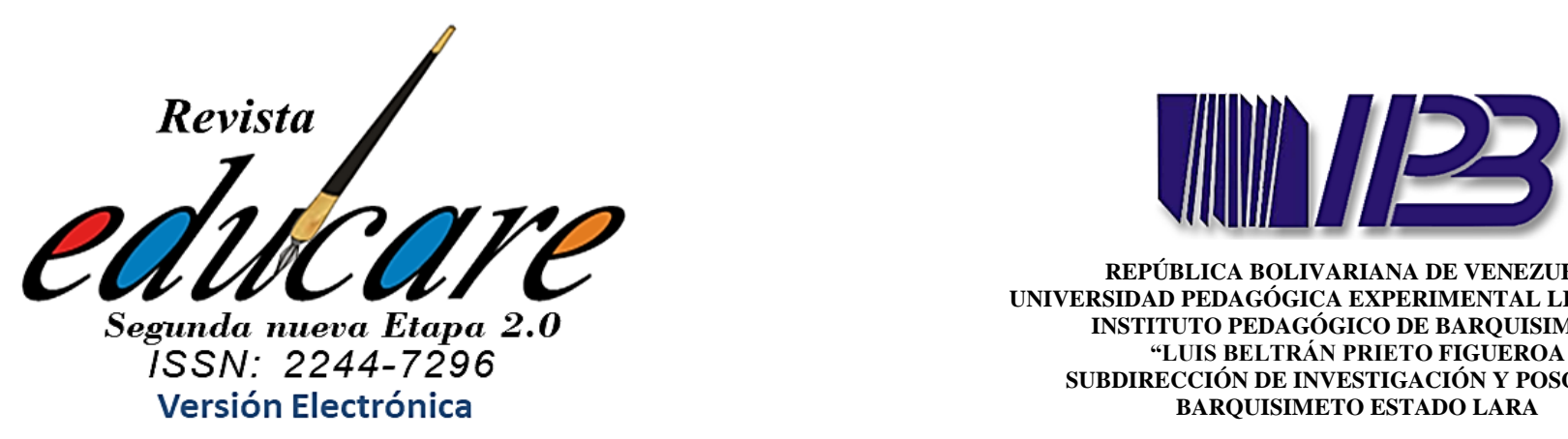

REPÚBLICA BOLIVARIANA DE VENEZUELA UNIVERSIDAD PEDAGÓGICA EXPERIMENTAL LIBERTADOR INSTITUTO PEDAGÓGICO DE BARQUISIMETO "LUIS BELTRÁN PRIETO FIGUEROA

SUBDIRECCIÓN DE INVESTIGACIÓN Y POSGRADO BARQUISIMETO ESTADO LARA

Volumen 24 № 1 Enero-Abril 2020

(75-97)

Cristi Liliana Bermúdez Aponte *

ORCID: https://orcid.org/0000-0002-7208-7972

MINISTERIO DE EDUCACIÓN
NACIONAL
COLOMBIA

* Docente de la Institución Educativa Presbítero Álvaro Suárez, Municipio de Villa del Rosario, Departamento Norte de Santander. Magíster en Gerencia Educativa UNET. Doctorante en Educación Universidad Pedagógica Experimental Libertador Instituto Pedagógico Rural Gervasio Rubio. Correo:cristyn2002@hotmail.com

\section{GESTIÓN DEL DOCENTE PARA EL FORTALECIMIENTO DE LA LECTURA COMPRENSIVA EN LA BÁSICA SECUNDARIA}

\author{
MANAGEMENT OF THE TEACHER FOR THE \\ STRENGTHENING OF COMPREHENSIVE \\ READING IN THE SECONDARY BASICS
}

\section{Recibido: \\ 18-12-2018 \\ Aceptado: \\ 01-11-2019}



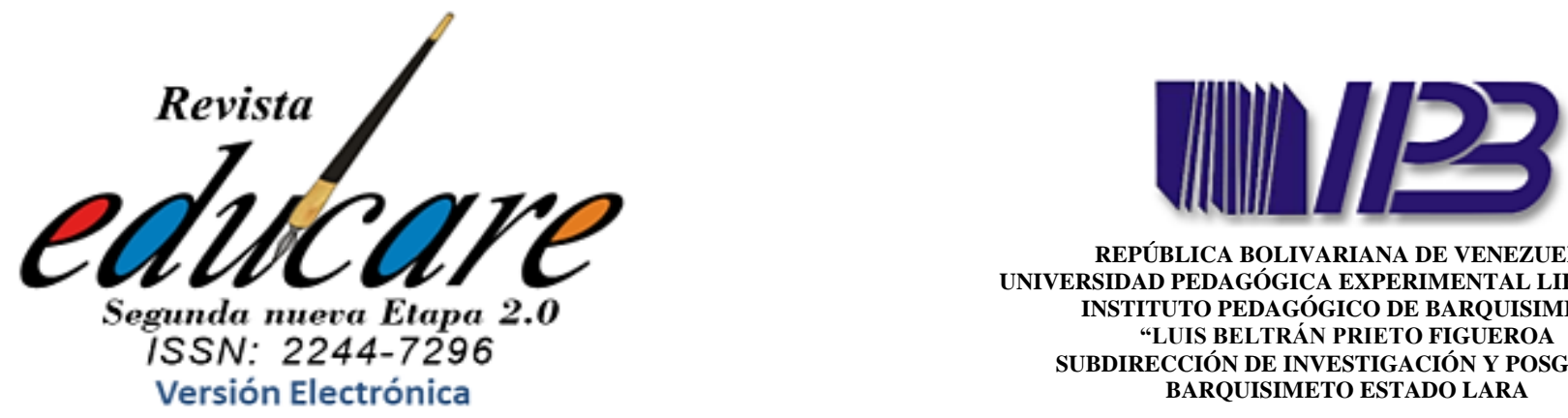

REPÚBLICA BOLIVARIANA DE VENEZUELA UNIVERSIDAD PEDAGÓGICA EXPERIMENTAL LIBERTADOR INSTITUTO PEDAGÓGICO DE BARQUISIMETO "LUIS BELTRÁN PRIETO FIGUEROA

SUBDIRECCIÓN DE INVESTIGACIÓN Y POSGRADO BARQUISIMETO ESTADO LARA

\section{GESTIÓN DEL DOCENTE PARA EL FORTALECIMIENTO DE LA LECTURA COMPRENSIVA EN LA BÁSICA SECUNDARIA}

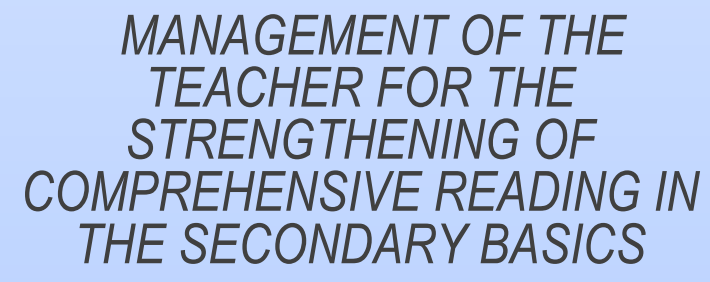

\section{Resumen}

La presente investigación estuvo orientada a diagnosticar desde la perspectiva del docente la lectura comprensiva de los estudiantes de básica secundaria y analizar la gestión docente en el fortalecimiento de los niveles de la lectura comprensiva en los estudiantes de básica secundaria de la Institución Educativa "Presbítero Álvaro Suárez", municipio Villa del Rosario, departamento Norte de Santander El estudio se ubicó en el enfoque cuantitativo, nivel descriptivo, de campo no experimental transeccional. Se trabajó con una muestra de 30 docentes, a quienes se les aplicó un cuestionario de 17 ítems de cinco opciones de respuestas: siempre, casi siempre, algunas veces, casi nunca y nunca, validado mediante la técnica juicio de expertos y hallada la confiabilidad a través del coeficiente Alfa de Cronbach obteniéndose un valor de 0,83 Se concluyó que el proceso de lectura comprensiva en los estudiantes es medianamente reforzado por los docentes, en consecuencia, existe un bajo nivel de comprensión lectora y escaso análisis crítico.

Descriptores: gestión docente, lectura comprensiva, estrategias gerenciales.cognitivas, interacción

\section{Abstract}

The present investigation was oriented to diagnose from the perspective of the teacher the comprehensive reading of secondary school students and analyze the teaching management in strengthening the levels of comprehensive reading in secondary school students of the "Prebístero Álvaro Suárez" Educational Institution, Villa del Rosario municipality, Norte de Santander department The study was based on the quantitative approach, descriptive level, of non-experimental field of translation. We worked with a sample of 30 teachers, to whom a questionnaire of 17 items of five response options was applied: always, almost always, sometimes, almost never and never, validated by the expert judgment technique and found the reliability to through the Cronbach's alpha coefficient obtaining a value of 0.83 It was concluded that the process of comprehensive reading in students is moderately reinforced by teachers, consequently, there is a low level of reading comprehension and little critical analysis.

Keywords: teaching management, comprehensive reading, management strategies. 


\section{INTRODUCCIÓN}

La educación es un factor de suma importancia en el desarrollo de un país, no sólo sustenta el futuro de una nación, sino que es la base del desarrollo estratégico del ser humano, lo dignifica y lo hace crítico de las situaciones que se le presentan para asumir actitudes asertivas ante las distintas problemáticas presentes en su región, país y continente. En ese sentido, la calidad de la educación, se mide por la eficacia y eficiencia de cómo funciona el sistema educativo, reto actual que exige la sociedad al mismo, para lograr una formación integral de sus ciudadanos.

Desde este desafío, surge la necesidad de mejorar en el docente su disposición para transformar su gestión y de asumir su compromiso como líder educativo, que se desenvuelva en su práctica pedagógica con pertinencia en los contenidos de la enseñanza, con suficiente fortaleza intelectual, que mantenga una firme amplitud de pensamiento, con una visión creativa, para que responda efectivamente a la formación integral del educando, fundamentado en habilidades que faciliten la coordinación de esfuerzos en acciones de trabajo, para el logro de objetivos compartidos de acuerdo con las nuevas realidades, necesidades del aprendizaje y la convivencia de una acción humanizadora y transformadora de la generación de relevo.

En el caso de Colombia se ha dado importancia a la educación a través de las distintas políticas gubernamentales, como lo afirmó Vélez (2007), "La Gestión Educativa: un reto para cambiar las instituciones, volverlas más eficientes, con resultados más eficaces” (p. 1). En este sentido, el Estado colombiano ha realizado esfuerzos que buscan la inclusión de la mayoría de niños y jóvenes en los procesos educativos para lograr su formación integral. No obstante, se observan inconvenientes que minimizan la eficacia de la gestión educativa, por una parte, la brecha existente en la distribución del rubro económico que le asigna un porcentaje muy bajo a la educación, y por otro lado, se encuentra el requerimiento de aumentar el número de educandos atendidos por aula, donde se evidencia una población mayor a 45 estudiantes (situación que disminuye la calidad de la enseñanza al disgregar la atención que se le presta a cada individuo), sumándose la falta de formación permanente del docente de aula, quien recurre a estrategias tradicionales.

Esta situación ha generado dificultades en la calidad educativa del país que se refleja en 
la Prueba SABER aplicada por el Instituto Colombiano para la Evaluación de la Educación (ICFES) en 2014 (Bustamante, 2015), los resultados demostraron que los estudiantes de primaria y secundaria no muestran progresos significativos en su desempeño en las pruebas de lenguaje, ya que de los 2,4 millones de niños que tomaron la prueba, el nivel de comprensión lectora es apenas aceptable: el puntaje promedio de las tres pruebas está entre los 300 y los 313 puntos, en una escala que va de 100 a 500 puntos. Esto quiere decir que la mayoría de los estudiantes del país apenas son capaces de comprender y explicar los elementos de la estructura cohesiva a nivel de oraciones y párrafos de textos cortos, explicativos o informativos.

Teniendo en cuenta lo anterior, la lectura no es un hábito en la mayoría de los estudiantes de educación primaria y secundaria, incluso universitaria. Este problema reside en el ambiente en el que se desarrollan: familia, escuela, comunidad, entre otros, que inciden de manera determinante para que ello ocurra. En este sentido, las instituciones educativas están en la obligación de fomentar hábitos de lectura en los estudiantes, para ello el docente debe gestionar desde el aula de clase, una diversidad de estrategias que motiven a éstos a leer, pues como lo afirma Solé (2012), el proceso de lectura debe asegurar la comprensión a través de la puesta en marcha de diferentes acciones que permitan a quien lee activar sus conocimientos previos para construir ideas sobre el contenido, organizar la información relevante, detenerse cuando lo requiera e incluso regresar y reflexionar; esto significa que el docente debe desarrollar espacios de acercar al estudiante a lectura con la finalidad de que se desenvuelva y participe activamente en la sociedad, dado que ésta posibilita el diálogo y la discusión.

Por otra parte, cabe mencionar el estudio sobre el Progreso Internacional en Competencias en Lectura (PIRLS, 2011), en el cual participaron 48 países, entre ellos Colombia, tuvo por objeto establecer una proyección de trabajo continuo en el campo de la evaluación de las competencias en lectura de los niños entre los 9 y 10 años de edad, quienes por lo general, se encuentran cursando el cuarto grado de educación básica primaria. Además de las pruebas, PIRLS aplica cuestionarios dirigidos a estudiantes, padres de familia, docentes y rectores de las instituciones educativas para obtener información sobre características personales, familiares y escolares que pueden estar incidiendo en el desempeño en esta prueba.

Es la segunda vez que Colombia participa, la primera vez fue en el año 2001 y los resultados reflejaron el esfuerzo del Ministerio de Educación Nacional (MEN) por alcanzar estándares internacionales elevados. Sin embargo, Colombia ocupó el lugar 39 en los resultados 
finales, aunque, comparando el primer estudio con el segundo, Colombia ascendió 25 puntos de calificación con respecto al logrado en el 2001. Además, el estudio agrega: "Colombia es el país en el que menos libros hay en las casas de los estudiantes y esto se ha visto como un factor que tiene mucha relación con los resultados” (p. 1). Razón por la cual, el docente está llamado a crear estrategias que faciliten la vinculación escuela-familia-comunidad, en búsqueda de alcanzar un mejoramiento educativo. Él asume un rol crucial en este proceso de acuerdo con los requerimientos y necesidades que demanda la sociedad, para responder de forma efectiva, desarrollando una concepción del docente como gestor de las transformaciones educativas, siendo consecuente con los desafíos actuales.

De acuerdo con lo anterior, se puede establecer una larga lista de factores que inciden en el resultado de los problemas lectores de la población estudiantil colombiana. Por el momento se hace referencia a la institución educativa objeto de estudio, Presbítero Álvaro Suárez, ubicada en Villa del Rosario, departamento Norte de Santander, en la cual, a partir de la experiencia como docente, la autora de la presente investigación ha observado en los estudiantes de básica secundaria, desinterés por la lectura, lo cual genera dificultad en la comprensión de los textos, escaso análisis lógico de los documentos, nivel básico de la comprensión lectora, se muestran satisfechos con el solo hecho de leer como un acto autómata de pronunciación y vocalización, una lectura decodificadora y repetitiva del texto, trayendo consigo dificultades en la interpretación asertiva del mensaje.

En este sentido, se denota que solo una minoría comprende lo que lee y elabora juicios propios, carecen del manejo de las competencias comunicativas y demuestran inhabilidad para relacionar conceptos, lo que impide el manejo de las competencias del área (interpretativa, argumentativa, propositiva) para el nivel de estudio que cursan. Se observa en algunos estudiantes apatía, poco interés por desarrollar el proceso de lectura comprensiva, escasa capacidad de asombro y de curiosidad, así como indiferencia por dedicar tiempo a la lectura.

Así que, en la referida institución educativa se observan situaciones que parecieran indicar la necesidad de una reconsideración en la gestión del docente para el fortalecimiento de la lectura comprensiva en la básica secundaria, porque existe escasa práctica de lectura durante el desarrollo de las actividades académicas, se denota exigua participación de los docentes en jornadas de promoción de lectura, escaso interés en el desarrollo de estrategias de lectura comprensiva, que disminuyen la motivación intrínseca y extrínseca hacia ese proceso. 
Igualmente, se presentan escasos canales de comunicación entre docentes y directivos para promover políticas gubernamentales sobre lectura comprensiva, lo cual afecta la comunicación asertiva que beneficie los momentos de clase para que los jóvenes accedan con mayor facilidad a los contenidos y procesos trabajados.

Con base a estas consideraciones, se establecieron como objetivos o propósitos de la investigación lo siguiente: Diagnosticar desde la perspectiva del docente la lectura comprensiva de los estudiantes de básica secundaria del instituto y analizar la gestión docente en el fortalecimiento de los niveles de la lectura comprensiva en los estudiantes de básica secundaria de la referida IE.

\section{MARCO TEÓRICO}

\section{Lectura Comprensiva}

No se puede hablar de comprensión de lectura sin determinar que se entiende por leer. Para Gómez (2011), "Leer es un proceso muy complejo que comprende una etapa sensorial en donde intervienen fundamentalmente los ojos y una etapa cerebral en la cual se elabora el significado de los símbolos impresos..." (p. 2). De modo que, el estudiante al abordar un texto no solo debe percibir los signos y unidades sintácticas (frases, oraciones, periodos, etc.) sino también comprender el significado de lo escrito, tratando de interiorizar en lo que el autor ha querido y logrado expresar. Se puede inferir que leer es comprender lo explícito y lo implícito en un texto, es encontrar el sentido del texto partiendo de un proceso complejo de pensamiento y acción.

Por consiguiente, leer dista mucho de ser un concepto simple, la lectura es uno de los procesos más complejos y amplios que puede realizar la mente humana, porque va desde los procesos básicos de percepción y atención hasta los procesos de elaboración de significado; va más allá de la simple decodificación y comprensión del sentido superficial del texto. Además, leer no solo es un proceso que se refiere al lenguaje verbal, también es necesario leer las imágenes, los textos publicitarios, los gestos, porque representan un compendio de información verbal y no verbal.

Asimismo, leer implica la construcción de un criterio propio frente a la información que circula en los medios masivos de información, un buen lector hoy, no es aquel que asimila mucha información, es quien logra, además de comprender, extraer conclusiones y tomar 
posición frente a la información. Leer también implica relacionar lo que dice un texto, con información de otros textos y con los conocimientos previos que se poseen. En síntesis, un buen lector es quien logra formar un criterio que le permite seleccionar y filtrar información, para estar en condiciones de construir un punto de vista propio.

Según Achaerandio (2009), "si consiguiéramos aumentar significativamente el número de ciudadanos que sepan leer comprensivamente, produciríamos la más importante revolución educativa, cultural y social de nuestra historia" (p. 1), esto demuestra la preeminencia de la lectura en todas las esferas, el valor social y la trascendencia de este proceso.

En este orden de ideas, existen distintos modelos que explican los procesos implicados en la lectura comprensiva, pero el que se considera más pertinente para el presente estudio es el denominado: Afectivo-Interactivo-Contextual (AIC) presentado por Téllez (2004), como un enfoque amplio de investigación que:

Asuma gran parte de las aportaciones cognitivas, pero a la vez se replantee buscando una mayor presencia de las variables afectivas y emocionales que pueden participar en el proceso lector, y de las variables contextuales en las que se desarrolla la lectura (p. 150).

De acuerdo con Téllez recomienda tener en cuenta factores de tipo afectivo y contextual, porque el proceso de lectura es dinámico, interactivo y en él influyen diversos factores, no sólo los cognitivos y procedimentales. Es importante porque toca un eje central en la presente investigación y es la participación de distintas variables afectivas como la actitud, motivación y las sensaciones físicas.

Otro punto importante que toca el autor, es acerca de las estrategias de lectura que se deben conocer, desde el punto de vista cognitivo y metacognitivo, así como las estrategias de aprendizaje que al final confluirían en un mismo fin: aprender a aprender, lo cual implicaría no solo el aprendizaje de discriminaciones visuales son también incluiría una serie de estrategias que van a facilitar la combinación de la información proporcionada por el texto y la procedente de los conocimientos del sujeto (González, 2014).

Por ello, es imprescindible que los docentes tomen en cuenta estos aspectos, porque la población que converge a estudiar presenta diversidad de problemáticas sociales, carencias afectivas, familias separadas, entre otros, razón por las cuales se debe tener en cuenta el contexto, los factores afectivos, en especial la motivación intrínseca, porque de ellos mismos depende que avancen en cualquier proceso. Asimismo, se hace relevante acercar a los docentes 
a los postulados teóricos sobre el proceso de lectura comprensiva, para que reconozcan, identifiquen y logren trabajar desde sus áreas en el mejoramiento de la lectura comprensiva, ofreciéndoles herramientas propicias para alcanzar esta finalidad y se conciencie la práctica del trabajo colaborativo en beneficio del estudiante y por la satisfacción del bien logrado con responsabilidad.

De igual manera, al hacer partícipe a los estudiantes de su proceso, reconocerán las competencias trabajadas, se logrará lo que se busca y se espera de ellos, como es un mayor contacto entre el texto, el contexto y sus necesidades, mejorando con ello su actitud comprensiva hacia la lectura, vista desde una perspectiva formativa, dinamizadora e integradora, sin olvidar los aspectos afectivos que juegan un papel relevante, porque si hay motivación el proceso de lectura comprensiva se lleva a cabo de manera más efectiva.

En el proceso de promoción de lectura, los docentes son actores claves en el fomento de la misma, pues en ellos recae la gran responsabilidad ante la sociedad, como es formar integralmente a los niños y jóvenes y prepararlos para su inserción en el campo laboral, con sólidas bases conceptuales y valores bien infundados. Por lo anterior, se infiere que un buen promotor de lectura es el que entrelaza el conocimiento con el dejar leer y la técnica que posee para enseñar y promover la lectura. Razón por la cual es de importancia relevante que el docente como líder, como animador, busque y propicie ambientes motivadores para que el proceso lector se genere y se fortalezca en todas las áreas del conocimiento.

Por lo tanto, la actual gestión del docente está en propiciar procesos de cambio y mejoramiento de la calidad de vida de los estudiantes, brindándoles acompañamiento en sus procesos de desarrollo mental y afectivo, incluyendo el ser promotor de la lectura en el nivel de educación básica secundaria, para lograr el aprendizaje significativo a partir de la lectura comprensiva en los estudiantes.

En alusión a la lectura comprensiva, tiene como antesala el acto de leer; en este sentido leer es un proceso intelectual y cognitivo que permite al estudiante obtener información a partir de un texto o cualquier material escrito. En relación con este término, Sernaque, Valencia y Gamonal (2015), consideran que "la comprensión lectora "es un proceso cognitivo que consiste en la construcción de significados haciendo uso de habilidades según el propósito que nos lleva a leer" (p. 9). Por su parte, Rosales y Cordero (2016), refieren "la comprensión lectora es la facultad intelectual que permite al lector entender, interpretar, organizar, ordenar, jerarquizar, 
relacionar la información escrita y hacer proyecciones sobre las ideas plasmadas en el texto" (p. 7). Según estos autores, la comprensión lectora es una habilidad, destreza o facultad cognitiva, que permiten no sólo decodificar un texto, sino que, también comprender un texto leído, interpretando la globalidad del mismo.

Con respecto a lo anterior, en la lectura comprensiva se pueden identificar diferentes niveles, reconocidos por diversos autores, aunque denominados de manera distinta. De Zubiría (2006), hace una clasificación en el proceso que se debe tener en cuenta al momento de potenciar la lectura, para llegar al culmen de la comprensión y el entendimiento, define estos niveles de lectura que van desde la interpretación de signos gráficos hasta la emisión de un juicio crítico pasando por el análisis. Menciona dicho proceso en seis etapas, el cual denomina Teoría de las Seis Lecturas, que presenta una estructura progresiva que inicia con la etapa fonética, referida al análisis y síntesis de los fonemas, pasando luego a tres etapas de decodificación denominadas: primaria, secundaria y terciaria, con respecto a su orden de profundidad; siguiendo con la llamada lectura categorial que consiste en la estructura argumental y derivativa del ensayo, y como última etapa propone la lectura meta semántica, donde se contrasta la obra con el autor, la sociedad y los productos de la cultura.

Dicho postulado citado emana de la pedagogía conceptual, poniendo de manifiesto que es realmente importante partir de los procesos mentales según la edad cronológica y evolutiva de cada individuo, cada aspecto es progresivo y debe ser evaluado de manera integral, porque cada individuo desarrolla sus procesos en correspondencia con su personalidad y contexto en el que se desenvuelve. Asimismo, se menciona que los estudiantes de sexto a octavo grado deben manejar la decodificación terciaria, y los estudiantes de noveno grado la lectura categorial.

Por su parte, Rosales y Cordero (2016), presentan una estructura de lectura comprensiva en cuatro niveles: (a) el nivel literal, que se centra en lo explícito del texto, intervienen procesos cognitivos como la identificación o los niveles básicos de discriminación; (b) el nivel inferencial, es una comprensión más profunda del texto se formulan hipótesis sobre el contenido del texto a partir de los indicios, estas se van verificando mientras se va leyendo; (c) el nivel crítico, donde surgen juicios de valor por parte del lector, quien estará en la capacidad de hacer deducciones, juzgar y llegar a conclusiones, en este nivel el estudiante tiene que activar procesos de análisis y síntesis, de enjuiciamiento y valoración y; (d) el nivel apreciativo, que representa la respuesta emocional a lo leído. 
Asimismo, el Ministerio de Educación Nacional (2008), en sus lineamientos curriculares, propone unos niveles de lectura comprensiva que ha definido como referentes para caracterizar modos de leer; dichos niveles no se asumen de manera tajante, definitiva, sino como una opción metodológica para caracterizar estados de competencia en la lectura. Estos son: (a) nivel A literal, en el que hay dos variantes: la literalidad transcriptiva y la literalidad en el modo de la paráfrasis; (b) Nivel B inferencia, implica "establecer relaciones y asociaciones entre los significados, lo cual conduce a formas dinámicas y extensivas del pensamiento" (p. 150); y (c) nivel C crítico-intertextual, la puesta en red de saberes de múltiples procedencias.

En fin, la conceptualización estructural aportada por los autores citados se relaciona en la mecánica progresista y jerarquizada que presenta en su configuración, donde el primer nivel es el acercamiento de menor complejidad, y el último nivel caracteriza a un lector ideal quien aprovecha al máximo la información que el texto le provee. Teniendo presente cada uno de los autores mencionados se opta por la jerarquización presentada por Rosales y Cordero (2016), puesto que presenta de forma sencilla y con una amplitud mayor, la integración de los elementos que le dan sentido a la lectura comprensiva, además de la concordancia que guarda con los lineamientos curriculares del Ministerio de Educación Nacional de Colombia.

\section{Gestión Docente}

El docente como eje central del proceso de fortalecimiento de la lectura comprensiva en los estudiantes de básica secundaria, manifiesta una serie de características que encaminan adecuadamente su quehacer pedagógico y formativo, asumiendo funciones propias de su ejercicio gerencial que delimitan y conllevan a un atinado progreso y superación de dificultades.

En este sentido, el trabajo del docente como gerente de aula es coordinar y supervisar las acciones para que se logren los objetivos de la institución educativa. Por consiguiente, es imprescindible la preparación constante del profesional de la docencia, de manera de que éste ejerza una gerencia de aula, sobre todo, porque la gerencia de aula según Castellanos (2006), está referida a todo lo que el docente hace en el aula que no es instruccional, en donde él, aparte de ser un efectivo y eficiente maestro, es un efectivo gerente de tiempo, tarea social, manejo de conflicto, comunicación, toma de decisiones, cambio, diseños físicos, tarea académica, motivación innovación, entre otras, asimismo, se deben efectuar cuatro funciones: la 
planificación, la organización, la dirección y el control.

Stephen y Decenzo (2003), afirman "la planificación es definir objetivos, establecer estrategias para lograrlos, desarrollar planes para integrar y coordinar las actividades" (p. 79). Es decir, durante esta primera función se establecen los objetivos, se fijan las estrategias para alcanzarlos, y se trazan planes para coordinar las actividades, por consiguiente, la gestión del docente debe encaminarse a la planificación de actividades especificando propósitos, tiempo y administración de recursos; igualmente, debe orientar los esfuerzos de sus educandos al logro de las metas propuestas. Una institución educativa que no planee está destinada al fracaso, un gerente de aula que no prepare y delimite su camino a seguir estará sentenciado a formar a sus educandos de manera insuficiente, ofreciendo a la sociedad un ciudadano sin objetivos y sin plan de vida.

En el fomento de la lectura comprensiva si no hay planeación estratégica, se creará una problemática cada vez más difícil de superar, porque los niños que van avanzando de nivel educativo llevarán consigo las limitaciones que nunca fueron superadas por falta de objetivos claros para cada año lectivo, y al finalizar, cuando se enfrenten a las pruebas de calidad no estarán preparados para ellas.

Por otra parte, Stephen y Coulter (2009), definen la organización como "determinar lo que es necesario realizar, cómo llevarlo a cabo y con quién se cuenta para hacerlo, acordar y estructurar el trabajo para cumplir con las metas" (p. 153). En este sentido, la organización consiste en determinar que tareas se deben realizar, quienes estarán a cargo, como se coordinarán los esfuerzos y el trabajo de acuerdo a los perfiles y habilidades que cada uno posea, para manejar adecuadamente los recursos presentes en beneficio de la organización educativa.

Para llevarse adecuadamente el proceso de lectura comprensiva, se pone de manifiesto la importancia de los estándares de calidad de Lengua Castellana, y los planes trazados por el Ministerio de Educación Nacional para el mejoramiento de la educación colombiana, partiendo de un punto importante, trabajar en equipo con los docentes de todas las áreas, quienes deben apropiarse de los lineamientos curriculares de lenguaje para profundizar desde su quehacer en la lectura comprensiva, asimismo, informarse sobre los programas que conciernen al fortalecimiento de la lectura comprensiva e impulsarlos desde sus clases.

Continuando con las funciones administrativas se encuentra la dirección. Stephen y 
Decenzo (2003), consideran que "incluye motivar a los empleados, orientar las actividades de otros, elegir el canal más eficaz de comunicación y resolver los conflictos que se presenten” ( $p$. 255). Es decir, requiere de parte de todo docente como gerente de aula, una motivación permanente tanto intrínseca como extrínseca, liderazgo, negociación y manejo de conflictos, comunicación asertiva, además demanda el contacto cotidiano con todos los integrantes de la comunidad educativa para guiarlos, orientarlos, e inspirarlos hacia el logro de las metas propuestas, incluye que todos hablen un mismo lenguaje en pro de los objetivos propuestos en la promoción de la lectura comprensiva.

Por esta razón, se requiere de la capacitación del docente dentro del proceso de fortalecimiento de la lectura compresiva en la básica secundaria, la realización de encuentros permanentes para no solo establecer metas, formular planes sino mantener la motivación que se vea reflejada en el buen direccionamiento de las estrategias planteadas y de su posterior realización.

Otra función gerencial que debe asumir el docente es el control, que según Cóndor (2013), es "el proceso de vigilar el desempeño, compararlo con las metas y corregir todas las desviaciones sustantivas" (p. 23). Implica observar de manera objetiva el desarrollo de las actividades propuestas, el desempeño de cada integrante para el cumplimiento de los objetivos, haciendo una retroalimentación de las situaciones presentadas en la planificación y detallar los resultados obtenidos para reforzar conductas o tomar correctivos de ser necesario, para lo cual se requiere del seguimiento al cumplimiento de las actividades planeadas, como son la observación sistemática del progreso de los jóvenes en su proceso de lectura comprensiva mediante el mejoramiento de sus pruebas escritas y orales, así como el mejoramiento en las estrategias empleadas por los docentes para lograr este propósito

Además de los procesos administrativos que debe cumplir el docente como gerente de aula, debe poseer habilidades gerenciales inherentes al contexto en que desempeña su labor. En particular, debe conocer las tendencias administrativas y pedagógicas, y la manera en que ellas deben complementarse, en este sentido, el docente ha de fungir como gerente educativo, aplicando lo que Koontz y Weihrich (2010), denominan habilidades técnicas, humanas, y conceptuales, las cuales se describen a continuación.

Las habilidades técnicas, implican la capacidad de realizar una tarea especializada que comprende un método o proceso determinado. Los gerentes dependen menos de sus habilidades 
técnicas básicas mientras más suben en una organización, pero éstas, le dan los antecedentes necesarios para sus nuevas responsabilidades, involucran el conocimiento y experiencia en determinados procesos, técnicas o herramientas propias del cargo o área específica que ocupa.

Por su parte, las habilidades humanas se relacionan con el trato con las personas; la capacidad de ser líder, de motivar y de comunicarse eficazmente con los demás. Es la capacidad que debe tener un gerente para interactuar con muchos distintos de personas y de intercambiar información con ellas, se refieren a la destreza de interactuar efectivamente con la gente, un gerente educativo interactúa y coopera con sus compañeros, y comunidad educativa en general, creando un clima laboral propicio para el logro de las metas y objetivos trazados.

En cuanto a las habilidades conceptuales, es la capacidad del gerente para reconocer aspectos complejos y dinámicos, de analizar los numerosos y conflictivos factores que éstos conllevan y resolver los problemas en beneficio de la organización y de sus miembros. Tales decisiones tienen un efecto profundo en el éxito de la organización, se relacionan con la formulación de ideas, entender las relaciones abstractas, desarrollar nuevos conceptos, resolver problemas en forma creativa.

La importancia de estas habilidades en el docente como gerente de aula, específicamente en la educación básica secundaria es crucial, el objetivo lo constituye el logro de un aprendizaje significativo que involucre la formación integral del educando en cuanto al fortalecimiento de la lectura comprensiva; además de permitir la adquisición de los niveles de lectura comprensiva en un contexto de interés para el estudiante, que le facilite el hacer, le fortalezca el ser y prepare al escolar para el saber hacer, es decir, para aprender procedimientos que deben seguirse en el proceso de la lectura comprensiva.

\section{ASPECTOS METODOLÓGICOS}

La investigación se ubica en un enfoque cuantitativo y la información recolectada fue procesada mediante técnicas estadísticas mostrándola en cuadros de distribución de frecuencias a fin de realizar la interpretación de los datos recopilados. En este sentido, Hernández, Fernández y Baptista (2014), refieren que este enfoque "Utiliza la recolección de datos para probar hipótesis con base en la medición numérica y el análisis estadístico, con el fin establecer pautas de comportamiento y probar teorías" (p. 4). 
También se enmarca en un nivel descriptivo porque según los citados autores "los estudios descriptivos buscan especificar las propiedades, las características y los perfiles importantes de personas, grupos, comunidades o cualquier otro fenómeno que se someta a análisis" (p. 92). Por consiguiente, se describe cómo es la gestión del docente para el fortalecimiento de los niveles de la lectura comprensiva y cuál es el nivel de la lectura comprensiva en los estudiantes de básica secundaría de la Institución Educativa Presbítero Avaro Suárez.

En relación con el diseño se sustentó en una investigación de campo pues se recolectaron datos sobre la gestión del docente y la lectura comprensiva en los docentes de la Institución Educativa Presbítero Álvaro Suárez, ubicada en el municipio Villa del Rosario, departamento Norte de Santander, sin realizar una manipulación deliberada de las variables, observándose tal como se viene presentando en el ámbito de estudio.

Sobre la población objeto de estudio estuvo conformada por 30 de docentes de básica secundaria, tomándose en su totalidad, a quienes se les aplicó una encuesta bajo un formato de cuestionario de 34 ítems, con cinco opciones de respuestas: siempre, casi siempre, algunas veces, casi nunca y nunca, el cual fue validado mediante la técnica juicio de expertos y hallada su confiabilidad mediante el alfa de Cronbach que arrojó un coeficiente de 0,83 que se ubica en un rango de muy alta confiabilidad.

\section{RESULTADOS}

\section{Lectura Comprensiva}

Con el objetivo de diagnosticar el nivel de la lectura comprensiva en los estudiantes de básica secundaria de la Institución Educativa Presbítero Álvaro Suárez, municipio de Villa Del Rosario, departamento del Norte de Santander, se presenta en el Cuadro 1 los resultados de los indicadores: literal, inferencial, crítico y apreciativo. 


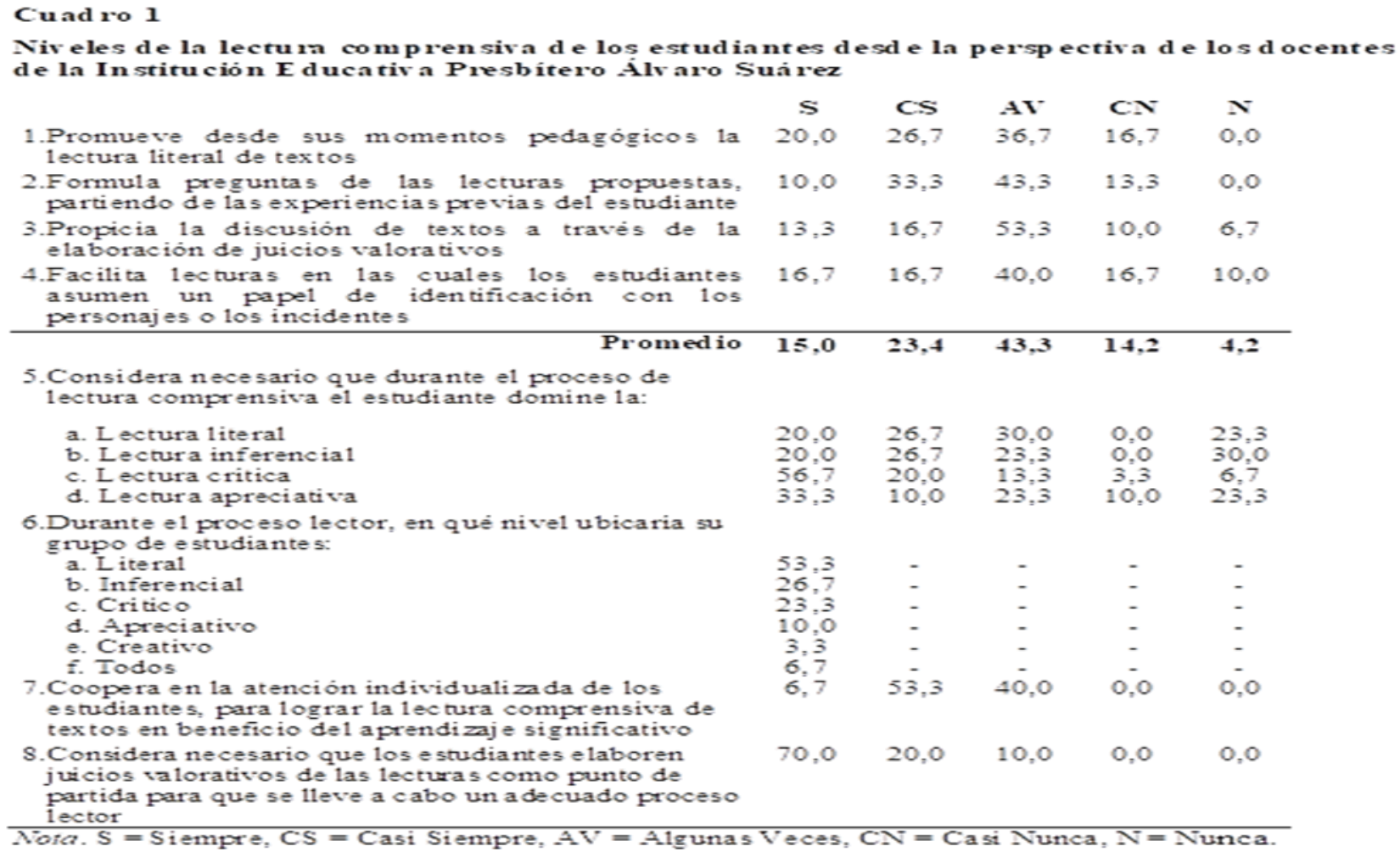

Del cuadro 1 se observa que el $36,7 \%$ de los docentes algunas veces promueven desde sus momentos pedagógicos la lectura literal de textos; otro 43,3\% algunas veces formulan preguntas de las lecturas propuestas partiendo de las experiencias previas del estudiante; además, el 53,3\% algunas veces propician la discusión de textos a través de la elaboración de juicios valorativos y, el $40 \%$ de los docentes admitió que algunas veces facilitan lecturas en las cuales los estudiantes asumen un papel de identificación con los personajes o los incidentes.

De acuerdo con las respuestas emitidas por los docentes, solo un promedio del $15 \%$ aseguran que siempre hacen uso de los niveles: literal, inferencial, crítico y apreciativo para desarrollar la lectura comprensiva en los estudiantes, en cambio, un 43,3\% algunas veces lo hace y otro 18,4\% casi nunca o nunca; por consiguiente, la mayoría de los docentes escasamente hacen uso de acciones pedagógicas orientadas al fortalecimiento de los niveles de la lectura comprensiva lo que sin lugar a duda poco contribuye en la adquisición de habilidades lingüísticas por parte de los estudiantes para la interpretación y comprensión critica del texto.

Lo anterior revela que al no fortalecerse los niveles de la lectura comprensiva descritos por Rosales y Cordero (2016), el nivel literal, que se centra en lo explícito del texto; el nivel inferencial, en el cual desde lo explícito, se realizan conjeturas de lo implícito del texto; el nivel 
crítico, donde surgen juicios de valor por parte del lector, y el nivel apreciativo, que representa la respuesta emocional a lo leído, podría no ayudar al estudiante a similar conceptos e ideas de manera sencilla cuando leen distintos textos, por ello, el docente desde su práctica pedagógica debe favorecer el desarrollo de ésta, con la intención que el estudiante sea capaz de entender, asimilar, relacionar y comprender lo que lee, de esta manera se fortalece el rendimiento académico y la calidad de la educación al obtener lectores consumados.

Al preguntársele a los docentes ¿cuál nivel de lectura comprensiva requiere ser dominado por el estudiante?, el 56,7\% de los docentes se inclinó por la lectura crítica; seguida de la lectura apreciativa con un $33,3 \%$, y de las lecturas: literal e inferencial, ambas con un $20 \%$. Es decir, la mayoría de los docentes encuestados coinciden sobre la necesidad que los estudiantes desarrollen la lectura crítica, valorada por Pinzás (2007) como el nivel más elevado de conceptualización, donde el lector emite juicios personales acerca del texto, valorando la relevancia o irrelevancia del mismo, el lector discrimina los hechos de las opiniones y logra integrar la lectura en sus experiencias propias.

Sin embargo, para que el estudiante alcance este nivel es necesario el desarrollo de los niveles literal e inferencial, esto implica que el estudiante debe comprender la información, ya que, si no comprende lo que el texto comunica, difícilmente puede hacer inferencias válidas y menos aún hacer una lectura crítica, lo cual resulta contradictorio la consideración de gran parte de los docentes en que durante el proceso de lectura comprensiva el estudiante domine la lectura crítica.

Igualmente se indagó en los docentes ¿En qué nivel de lectura ubicaría al grupo de estudiantes?, obteniéndose que un 53,3\% de los docentes consideran que el grupo de estudiantes a su cargo presentan un nivel de lectura literal, por cuanto éstos se conforman a leer lo que dice el texto, mientras un 26,7\% y 23,3\% estiman que el grupo hace uso de la lectura inferencial y crítica, y otro $10 \%$ ubican al grupo en el nivel apreciativo.

En tal sentido, el nivel de lectura comprensiva de mayor dominio en los educandos de la Institución Educativa Presbítero Álvaro Suárez, es el literal, que de acuerdo con Rosales y Cordero (2016), el lector tiene la capacidad de evocar sucesos o hechos tal como aparecen expresados en el texto. Es decir, gran parte de los estudiantes son capaces de reconocer y recordar los hechos tal y como aparecen expresos en la lectura y una vez adquiridas ya las destrezas decodificadoras básicas le permitan al escolar una lectura fluida. 
Otro aspecto a resaltar es que el 53,3\% de los docentes casi siempre cooperan en la atención individualizada de los estudiantes para lograr la lectura comprensiva de textos en beneficio del aprendizaje significativo, aunque un $40 \%$ lo hacen algunas veces. En este caso, pareciera que los docentes de la básica secundaria de la Institución Educativa Presbítero Álvaro Suárez, buscan atender individualmente a los estudiantes para que desarrollen habilidades de lectura comprensiva en los estudiantes, debido a la presencia de una cantidad significativa de educandos que se ubican en el nivel literal de la comprensión lectora, que no se corresponde con la edad y grado que cursa, sobre todo, cuando el docente desearía que el estudiante estuviese en un nivel más profundo que supone haber superado los niveles de comprensión literal y de comprensión inferencial, llegándose a un grado de dominio lector, caracterizado por emitir juicios personales acerca del texto, valorando la relevancia o irrelevancia del mismo.

Del ítem 8 se desprende que el $70 \%$ consideran necesario que los estudiantes elaboren juicios valorativos de las lecturas como punto de partida para que se lleve a cabo un adecuado proceso lector, lo cual corrobora que existe en los docentes una mayor preferencia por la lectura crítica; sin embargo, no todos los educandos han

llegado a este nivel, lo cual supone la necesidad de que el docente gestione estrategias pedagógicas adecuadas para lograr esta premisa de lectores consumados capaces de emitir juicios valorativos, comparando las ideas presentadas en la selección con criterios externos, o criterio interno dado por los saberes previos del estudiante, tal como lo señala Pinzás (2007), para interpretar y valorar, se requiere contar con puntos de vista para efectuar comparaciones, estos puntos de vista pueden ser las experiencias y vivencias del propio lector.

\section{Gestión Docente}

A continuación, se analiza la gestión del docente para el fortalecimiento de los niveles de la lectura comprensiva en los estudiantes de básica secundaria de la Institución Educativa Presbítero Álvaro Suárez, a través de los indicadores funciones administrativas (planificación, organización, dirección y control) y trabajo en equipo (comunicación, manejo de relaciones y participación). 
Cuadro 2

Gestión docente para el fortalecimiento de la lectura comprensiva en los estudiantes de educación básica de la Institución Educativa Presbítero Álvaro Suárez

\begin{tabular}{|c|c|c|c|c|c|}
\hline & $\mathbf{S}$ & CS & $\mathbf{A V}$ & $\mathbf{C N}$ & $\mathbf{N}$ \\
\hline $\begin{array}{l}\text { 9. Planea sus momentos pedagógicos de acuerdo con } \\
\text { los requerimientos del PEI institucional. }\end{array}$ & 30,0 & 56,7 & 10,0 & $\mathbf{O}, \mathrm{O}$ & 3,3 \\
\hline \multicolumn{6}{|l|}{ 10.Organiza su trabajo académico incluyendo: } \\
\hline a. Metas claras de aprendizaje & 63,3 & - & - & - & - \\
\hline b. Estrategias & 33,3 & - & - & - & - \\
\hline c. Tiempos & 10,0 & - & - & - & - \\
\hline d. Recursos & 10,0 & - & - & - & - \\
\hline e. Criterios de evaluación & 20,0 & - & - & - & - \\
\hline 11. Realiza seguimiento del proceso de comprensión de & 10,0 & 40,0 & 33,3 & 3,3 & 13,3 \\
\hline
\end{tabular}

lectura mediante los patrones establecidos por la institución.

12.Durante el proceso lector, considera necesario verificar la comprensión lectora a través de:

a. Preguntas generadoras

b. Torbellino de ideas

c. Producción de textos escritos espontáneos

d. Producción de imágenes relacionadas

13. Atiende oportunamente las inquietudes de comprensión lectora de los estudiantes.

14. Posee habilidades técnicas, que faciliten la práctica efectiva de la lectura comprensiva en beneficio del aprendizaje significativo de los estudiantes.

15. Aplica estrategias didácticas específicas teniendo en cuenta los conocimientos previos de los estudiantes durante la práctica de la lectura comprensiva.

16. Se integra pedagógicamente con los docentes especialistas de castellano y otros profesionales de la institución en atención a la lectura comprensiva de los estudiantes.

17. Selecciona del contexto general que circunda al estudiante los elementos más significativos para facilitar la lectura comprensiva en beneficio de la construcción del conocimiento.

Nota. $\mathrm{S}=$ siempre, $\mathrm{CS}=$ Casi Siempre, AV = Algunas Veces, $\mathrm{CN}=$ Casi $\mathrm{Nunca}, \mathrm{N}=\mathrm{Nunca}$.

En relación con las funciones administrativas se obtuvo lo siguiente: (a) el $56,7 \%$ de los docentes admitió que casi siempre planifica sus momentos pedagógicos según los requerimientos del PEI institucional; (b) en cuanto a la organización del trabajo académico, el 63,6\% incluye metas claras de aprendizaje y otro 33,3\% estrategias; (c) respecto a la dirección, el $40 \%$ casi siempre y un $33,3 \%$ algunas veces realizan seguimiento del proceso de comprensión de lectura mediante los patrones establecidos por la institución y; (d) acerca del control, la mayor parte de los educadores se inclinan por verificar la comprensión lectora a través de preguntas generadoras y producción de textos escritos espontáneos,

De estos resultados se desprende que la mayoría de los docentes de la institución educativa Presbítero Álvaro Suárez casi siempre gestionan actividades para el fortalecimiento de los niveles de la lectura comprensiva en los estudiantes de básica secundaria para que alcancen niveles superiores, teniendo en cuenta el interés del docente en que los estudiantes 
elaboren juicios valorativos de las lecturas como punto de partida para que se lleve a cabo un adecuado proceso lector. Por lo tanto, los docentes realizan en el aula de clase las funciones administrativas como: planificación, organización, dirección y control, permiten en opinión de Chiavenato (2006) “....utilizar sus recursos humanos, físicos y financieros con la finalidad de alcanzar objetivos..." (p. 146), las cuales están dirigidas al fortalecimiento de la lectura comprensiva con el propósito de alcanzar niveles críticos e interpretativos que desean los docentes posean los estudiantes.

También se observa entre las respuestas del personal docente como un $30 \%$ y algunas veces atienden oportunamente las inquietudes de comprensión lectora de los estudiantes, incluso un 20\% contestó casi nunca, solo el $10 \%$ respondió siempre; es decir, gran parte de los educadores de manera ocasional buscan desarrollar actividades orientadas a atender las necesidades de los estudiantes para el fortalecimiento de la comprensión lectora a fin de obtener niveles más altos, teniendo en cuenta que cada estudiante tiene un estilo de aprender, por lo que debe aplicar determinadas estrategias para ayudarles en su proceso lector, porque como lo afirma Achaerandio (2009), al leer el lector va asimilando, construyendo, modificando sus esquemas mentales, los cuales son representaciones que quedan grabadas en la mente y en el sistema neuronal del cerebro, que es su base biológica.

Por otra parte, un 13,3\% de los docentes reconoció poseer siempre habilidades técnicas, que faciliten la práctica efectiva de la lectura comprensiva en beneficio del aprendizaje significativo de los estudiantes, mientras un $40 \%$ respondió algunas veces, por lo tanto, gran parte de éstos admiten que al no poseer habilidades técnicas difícilmente podrán aplicar estrategias para fortalecer la comprensión lectora y con ello mejorar el aprendizaje de los estudiantes. Estos datos contradicen lo mencionado por Koontz y Weihrich (2010), quienes afirman que las habilidades técnicas implican la capacidad de realizar una tarea especializada que comprende un método o proceso determinado, de manera que si el docente no demuestra ser hábiles para involucrar el conocimiento y experticia en el proceso de la lectura, difícilmente logrará que los estudiantes desarrollen la comprensión lectora.

Asimismo, un $30 \%$ de los docentes aseguran que algunas veces aplican estrategias didácticas específicas teniendo en cuenta los conocimientos previos de los estudiantes durante la práctica de la lectura comprensiva, solo el $16,7 \%$ respondió siempre. De manera que la mayoría de los docentes tienden a no aprovechar los conocimientos previos de los educandos 
para hacer más efectiva el proceso de lectura comprensiva, a pesar del interés que manifiestan de que los estudiantes alcancen niveles superiores en la lectura.

Otro elemento que poco favorece la gestión del docente es la escasa integración pedagógica entre los docentes con sus colegas especialistas de castellano y otros profesionales, porque un $46,7 \%$ indicó hacerlo algunas veces y otro $23,3 \%$ casi nunca; por lo tanto, al no existir una exigua integración pedagógica dificulta la planificación de estrategias para lograr que los estudiantes alcancen un proceso lector adecuado, sobre todo, cuando la responsabilidad recae entre todos los docentes para lograr en el estudiante el desarrollo de habilidades de lectura comprensiva. Por lo tanto, lo observado en el ítem poco se ajusta a lo comentado por Koontz y Weihrich (2010) quienes refieren que una de las habilidades gerenciales que debe poseer el gerente es relacionarse con distintas personas e intercambiar información, de manera que se percibe dificultades para expresar capacidad de liderazgo con miras a integrar a los demás docentes para generar acciones conducentes en la formación de lectores críticos y autónomos en la sociedad actual.

Igualmente existe un $53,3 \%$ de los docentes que algunas veces seleccionan del contexto general del estudiante los elementos más significativos para facilitar la lectura comprensiva en beneficio de la construcción del conocimiento, solo un 13,3\% señalo hacerlo siempre, por lo tanto, pareciera ser que los docentes tienden a no aprovechar el contexto social donde se desenvuelven los estudiantes con el fin de introducir lecturas que contribuyan a la formación de un lector crítico para esta sociedad, donde la deconstrucción y análisis cultural e ideológico del discurso escrito son esenciales para el ejercicio de la ciudadanía.

\section{CONCLUSIONES}

Según los hallazgos encontrados en la presente investigación se aprecia que los docentes algunas veces promueven actividades pedagógicas para desarrollar en los estudiantes niveles superiores de comprensión lectora, sin embargo, la gran mayoría consideran pertinente que éstos dominen la lectura crítica, aun cuando los docentes conocen que los estudiantes se ubican en el nivel literal, demostrando con ello que apenas intervienen procesos cognitivos como la identificación o niveles básicos de discriminación, teniendo dificultades para hacer deducciones, juzgar y llegar a conclusiones, de allí que los docentes del estudio consideren 
necesario que los estudiantes elaboren juicios valorativos de las lecturas como punto de partida para que se lleve a cabo un adecuado proceso lector, aunque para ello es necesario que gestionen estrategias para atender las necesidades de alcanzar niveles superiores en la comprensión lectora. De tal manera que, las apreciaciones de los docentes llevan a reflexionar acerca de las estrategias pedagógicas empleadas para fortalecer la lectura comprensiva, las cuales no han sido eficientes, incluso por desconocimiento de algunos docentes en cuanto a los niveles de lectura y lo que corresponde a cada uno, así como coloca en evidencia la escasa puesta en práctica de actividades integradas con sus áreas de conocimiento que involucren la lectura comprensiva.

Sobre la gestión docente, se concluye que los sujetos del estudio tienden a integrar las funciones administrativas (planificación, organización, dirección y control) con la lectura comprensiva, pero les cuesta atender oportunamente las inquietudes de los estudiantes en materia de comprensión lectora, y esto sucede porque la apreciación de la mayoría es que no desarrollan a plenitud las habilidades gerenciales en beneficio del fortalecimiento de la lectura comprensiva, toda vez que en ocasiones facilitan la práctica efectiva de la lectura comprensiva en beneficio del aprendizaje significativo de los estudiantes, se integra pedagógicamente con los docentes especialistas de castellano y relaciona el contexto social del estudiante para hacer más eficiente la lectura comprensiva, por lo tanto, esto no favorece ubicar a los estudiantes en niveles superiores como es el deseo de los docentes de la Institución Educativa Presbítero Álvaro Suárez.

\section{RECOMENDACIONES}

Como producto de los hallazgos encontrados en la presente investigación, se recomienda que los directivos de la institución se involucren de manera comprometida, con pertinencia de la problemática presentada, con la finalidad de promover espacios de actualización constante para abordar los problemas de lectura comprensiva, también, brinden espacios pedagógicos de formación permanente, de manera periódica y se esfuercen porque los docentes a su cargo cuenten con las herramientas necesarias para superar las dificultades.

De igual manera, se recomienda incluir en el PEI de la institución actividades puntuales que exijan una planeación, control y evaluación permanente de manera transversal de la lectura comprensiva, abriendo espacios claves para ello, asimismo, generar conciencia de que el área 
de lenguaje no es la única encargada del desarrollo de las habilidades comunicativas, sino por el contrario, es un esfuerzo aunado que desde el liderazgo transformacional todos deben asumir.

\section{REFERENCIAS}

Achaerandio, L. (2009). Reflexiones acerca de la lectura comprensiva. Programa Centroamericano de Formación de Educadores en Servicio, de la Universidad Rafael Landivar, Guatemala. Recuperado de: http://courseware.url.edu.gt/DESAC1/Estudiantes/Lectura\%20y\%20Escritura\%20Acad\% C3\%A9micas/La\%20lectura\%20comprensiva\%20-\%20Achaerandio.pdf.

Arias, F. (2012). El proyecto de investigación: Introducción a la metodología científica. Caracas, Venezuela: Episteme.

Bustamante, N. (2015). Niños colombianos pasan raspando en habilidad lectora. Diario El Tiempo, 21-02-2015.

Castellanos, E. (2006) Gerencia de aula y estrategias de aprendizaje. Recuperado de: https://www.quieroapuntes.com/gerencia-de-aula-y-estrategias-de-aprendizaje.html.

Cóndor, E. (2013). Habilidades Gerenciales. Recuperado de: http://www.slideshare. net/edgarcondor/habilidades-gerenciales-16741474.

De Zubiría, M. (2006). Teoría de las seis lecturas. Tomo II Fundación Alberto Merani. (7 ed.). Colombia.

Gómez, J. (2011). Comprensión lectora y rendimiento escolar: una ruta para mejorar la comunicación.COMUNI@CCIÓN: Revista de Investigación en Comunicación y Desarrollo, 2(2), 1-10. Recuperado de: https://dialnet.unirioja.es/descarga/articulo/3801085.pdf.

González, F. (2014). Aprender a leer, leer para aprender. (Tesis de grado). Universidad del Biobío, Chile. Recuperado de: http://repobib.ubiobio.cl/jspui/bitstream/123456789/1677/1/Gonzalez_Vega_Carlos.pdf

Hernández, R; Fernández, C. y Baptista, P. (2014). Metodología de la investigación. México: McGraw-Hill / Interamericana S.A.

Koontz, H. y Weihrich, H. (2010). Administración. Una perspectiva global. México: McGraw-Hill

Ministerio de Educación Nacional (2008). Evaluación anual de desempeño laboral docente y directivos docentes, guía metodológica. Colombia: Autor.

Pinzás, J. (2007). Estrategias metacognitivas para desarrollar la comprensión lectora. Lima: Metrocolor. 
Progreso Internacional en Competencias en Lectura (PIRLS, 2011). Recuperado de: http://www.icfes.gov.co/pirls/.

Rosales, J y Cordero, H. (2016). Técnicas de la comprensión lectora. Lima, Perú: Talleres de ideas group EIRL.

Sernaque, W., Valencia, R. y Gamonal, M. (2015). Comprensión lectora guía del docente. Chosica, Perú: Universitaria.

Solé, I. (2012). Competencia lectora y aprendizaje. Revista Iberoamericana de Educación, (59), 43-61. Recuperado de: https://rieoei.org/historico/documentos/rie59a02.pdf.

Stephen, R., y Coulter, M. (2009). Management. México: Pearson educación, Prentice Hall.

Stephen, R., y Decenzo, D. (2003). Fundamentos de administración. (10 a Ed.). México: Pearson educación, Prentice Hall

Téllez, J. (2004). La comprensión de los textos escritos y la psicología cognitiva. Madrid: Dikynson, S.L.

Vélez, M. (2007). Gestión de la educación y calidad de la enseñanza. Recuperado de: http://www.oei.es/noticias/spip.php?article975\&debut_5 ultimasOEI=5. 